\title{
Exploiting Factor Autocorrelation to Improve Risk Adjusted Returns
}

\author{
Kevin Oversby ${ }^{\dagger}$
}

22 February 2014

\begin{abstract}
The Fama-French three factor model is ubiquitous in modern finance. Returns are modeled as a linear combination of a market factor, a size factor and a book-to-market equity ratio (or "value") factor. The success of this approach, since its introduction in 1992, has resulted in widespread adoption and a large body of related academic literature.
\end{abstract}

The risk factors exhibit serial correlation at a monthly timeframe. This property is strongest in the value factor, perhaps due to its association with global funding liquidity risk.

Using thirty years of Fama-French portfolio data, I show that autocorrelation of the value factor may be exploited to efficiently allocate capital into segments of the US stock market. The strategy outperforms the underlying portfolios on an absolute and risk adjusted basis. Annual returns are $5 \%$ greater than the components and Sharpe Ratio is increased by $86 \%$.

The results are robust to different time periods and varying composition of underlying portfolios. Finally, I show that implementation costs are much smaller than the excess return and that the strategy is accessible to the individual investor.

†Freelance Analyst, email: koversby@gmail.com, tel: (1) 6046031747 


\section{Introduction}

The Fama French Three Factor Model describes the expected return ( $r$ ) on an asset as a result of its relationship to three factors: market risk (Mkt), size risk (SMB), and "value" risk (HML):

$$
r=r_{f}+\beta\left(M k t-r_{f}\right)+s . S M B+h . H M L
$$

where $r_{f}$ is the risk-free return rate and the coefficients measure the exposure to each risk.

$\mathrm{SMB}$, which stands for Small Minus Big, measures the excess return received by investing in stocks of companies with relatively small market capitalization. This additional return is often referred to as the "size premium." SMB is computed as the average return for the smallest 30\% of stocks minus the average return of the largest $30 \%$ of stocks in that month.

$\mathrm{HML}$, which is short for High Minus Low, measures the "value premium" provided to investors for investing in companies with high book-to-market $(B / M)$ values. $H M L$ is computed as the average return for the $50 \%$ of stocks with the highest $B / \mathrm{M}$ ratio minus the average return of the $50 \%$ of stocks with the lowest $\mathrm{B} / \mathrm{M}$ ratio each month.

Since its introduction by Fama and French (1992), a vast literature has been published on all facets of the model from correlation with global economic factors (Asness, Moskowitz and Pedersen 2013) to practical applications to fund management (Doskov, Pekkala and Ribeiro 2013).

All three factors are time varying. This raises the following questions: 
1. Is it possible to reliably allocate capital to the factor(s) likely to outperform in the next period?

2. Do the costs of implementing such a strategy exceed the benefit?

3. Is this type of strategy accessible to the individual investor?

The focus of this paper will be on the application of one specific property of the factors. That property is the monthly serial correlation, or autocorrelation, of the factors as illustrated in table 1:

Table 1: Factor serial correlation (lag 1 month)

\begin{tabular}{|l|c|c|c|}
\hline & Mkt-RF & SMB & HML \\
\hline $\mathbf{1 9 7 5 - 1 9 8 5}$ & 0.05 & 0.12 & 0.19 \\
\hline $\mathbf{1 9 8 5 - 1 9 9 5}$ & 0.05 & 0.10 & 0.26 \\
\hline $\mathbf{1 9 9 5 - 2 0 0 5}$ & 0.05 & 0.25 & 0.25 \\
\hline 2005-present & 0.20 & -0.06 & 0.34 \\
\hline
\end{tabular}

Autocorrelation can be exploited to predict which segment of the market is likely to outperform in the next month. Historically, the HML factor exhibits the most stable autocorrelation and is therefore the primary focus of this paper. Kothari and Shanken (1998) note that if the B/M effect is related to risk and liquidity it can reasonably be expected to persist to some degree in the future. Asness, Moskowitz and Pedersen (2013) document liquidity effects in value and momentum returns. They find a positive relationship between value and liquidity risk.

Kothari and Shanken find that book-to-market effect is mainly concentrated in small firms. A paper by Loughran (1996) mirrors this finding for large firms. For the largest size quintile, which 
accounts for about three-quarters of all market value, he concludes that $\mathrm{B} / \mathrm{M}$ has no reliable predictive power for returns in the 1963-94 period.

For these reasons, this paper studies return data from portfolios with firm size below the NYSE median.

The rest of this paper is organized as follows. Section 2 describes data and methodology. Section 3 presents the empirical findings. Section 4 conducts the robustness checks and Section 5 concludes.

\section{Data and Methodology}

All raw data in this paper are taken from the on-line library provided by Kenneth French ${ }^{1}$. The portfolios are selected from the 6 portfolios formed on size and book-to-market. The precise definition, taken from the website, is as follows:

"The portfolios, which are constructed at the end of each June, are the intersections of 2 portfolios formed on size (market equity, ME) and 3 portfolios formed on the ratio of book equity to market equity (BE/ME). The size breakpoint for year $t$ is the median NYSE market equity at the end of June of year $\mathrm{t}$. BE/ME for June of year $t$ is the book equity for the last fiscal year end in $\mathrm{t}-1$ divided by $\mathrm{ME}$ for December of $\mathrm{t}-1$. The BE/ME breakpoints are the 30th and 70th NYSE percentiles.

1. http://mba.tuck.dartmouth.edu/pages/faculty/ken.french/data_library.html 
The portfolios for July of year $t$ to June of $t+1$ include all NYSE, AMEX, and NASDAQ stocks for which we have market equity data for December of $\mathrm{t}-1$ and June of $\mathrm{t}$, and (positive) book equity data for $\mathrm{t}-1$. "

I use 30 years of monthly total-return data in my analyses. Portfolios are value weighted. For the robustness checks in Section 4, equal weighted portfolios and 60 year histories are also used.

\subsection{Methodology}

A realistic strategy must use only information that was available to the investor in real-time. The strategy described below uses the autocorrelation property of the value factor, HML. This property was strongly evident since at least 1975 (table 1) therefore this criterion is satisfied.

One discussion point, which applies to many of these types of study, is that of trading costs. For more than a decade, suitable low-cost factor based funds have been available. However, in the 1980s and earlier, trading costs were higher and use of appropriate funds may not have been possible in lieu of individual stocks. The effect may be to reduce the level of realism as test length increases.

The HML factor is time varying and autocorrelated, therefore the sign of the factor is a good predictor of the following month's sign. A positive (negative) HML factor in the current month predicts value will outperform (underperform) growth next month. A strategy is proposed which switches $100 \%$ of capital monthly from value (high $\mathrm{B} / \mathrm{M}$ ) to growth (low $\mathrm{B} / \mathrm{M}$ ) based on 
the sign of the HML factor. This switching portfolio is itself autocorrelated therefore the strategy switches to risk-free if the previous monthly return is negative:

Let $\mathrm{R}$ be the monthly return with subscripts: $p$ portfolio, $v$ value, $g$ growth, $f$ risk-free and $t$ time:

$$
\begin{gathered}
R_{p, t}=R_{v, t} \text { if } H M L_{t-1}>0 \text { and } R_{p, t-1}>0 \\
R_{p, t}=R_{g, t} \text { if } H M L_{t-1}<0 \text { and } R_{p, t-1}>0 \\
R_{p, t}=R_{f, t} \text { if } R_{p, t-1}<0
\end{gathered}
$$

The value portfolio is the small high book-to-market Fama-French portfolio and the growth portfolio is the small low book-to-market Fama-French portfolio from the $2 \times 3$ series.

Many tactical portfolios use bonds as a non-correlated asset to reduce return volatility (e.g. Faber 2007). I choose to switch to risk-free rather than bonds to avoid biasing the results. Bonds have been in a bull market over the duration of the tests and typically negatively correlated with stocks. This return enhancer may not be available in the intermediate future, given that interest rates are currently close to zero.

\section{Results}

Table 2 lists the results and statistics of the strategy compared with the individual components. Sharpe Ratios are calculated relative to zero and annualized. I report the statistical significance of the null hypothesis of zero mean return (t-stat). Results are frictionless; costs are discussed later. 
Table 2: Results of the value-growth switching strategy

\begin{tabular}{|c|c|c|c|}
\hline 1984-2014 & VAL & GRO & switch \\
\hline SR & 0.7 & 0.7 & 1.1 \\
\hline t-stat & 3.7 & 3.8 & 5.9 \\
\hline CAGR & $13.4 \%$ & $10.6 \%$ & $15.3 \%$ \\
\hline $\mathbf{R}^{2}$ & $96.0 \%$ & $87.3 \%$ & $99.5 \%$ \\
\hline
\end{tabular}

SR Sharpe Ratio, CAGR Compound Annual Growth Rate, VAL Value, GRO Growth

The strategy annual return is $3.4 \%$ greater than the average of the base Fama-French portfolios. Sharpe Ratio increases from 0.7 to 1.1 , signifying improved returns on a risk-adjusted basis.

\subsection{Enhanced results}

Can this strategy be improved without adding complexity? Kothari and Shanken (1998) show that the growth portfolio has relatively low returns. Berger, Israel and Moskovitz (2009) describe an alternative and improved way to access growth: momentum. This anomaly is extremely robust and persists over most asset classes and time periods (Asness, Moskowitz and Pedersen 2013). They note that momentum is closely correlated with growth but with $3.3 \%$ greater annual returns from 1980-2009. The momentum portfolio has better performance, both in absolute terms and relative to a core index.

Israel and Moskowitz (2013) show that the momentum premium is present and stable across all size groups - there is little evidence that momentum is substantially stronger among small cap stocks over the entire 86-year U.S. sample period. The value premium, on the other hand, is largely concentrated only among small stocks. For consistency with the value portfolio, the small cap momentum portfolio is used. 
Replacing the growth portfolio with a momentum portfolio leads to the result in table 3 .

Table 3: Results of the value-momentum switching strategy

\begin{tabular}{|c|c|c|c|}
\hline 1984-2014 & VAL & MOM & switch \\
\hline SR & 0.7 & 0.8 & 1.3 \\
\hline t-stat & 3.7 & 4.4 & 7.1 \\
\hline CAGR & $13.4 \%$ & $16.1 \%$ & $19.7 \%$ \\
\hline R $^{2}$ & $96.0 \%$ & $95.8 \%$ & $99.7 \%$ \\
\hline Max. DD & $62.8 \%$ & $54.1 \%$ & $18.3 \%$ \\
\hline
\end{tabular}

SR Sharpe Ratio, CAGR Compound Annual Growth Rate, VAL Value, MOM Momentum

The annual return of $19.7 \%$ is $5.0 \%$ greater than the average of the component portfolios. Risk adjusted returns (measured by the Sharpe Ratio) increase by $86 \%$ over the value portfolio with a t-statistic of 7.1 and $R^{2}$ of $99.7 \%$.

The maximum drawdown (DD) is dramatically reduced from $62.8 \%$ to $18.3 \%$.

Figure 1 shows compounded growth of $\$ 1$ starting in 1984, for the value and momentum portfolios, and the switching strategy. The final worth of the strategy portfolio is about \$200.

The lower part of the plot depicts the state of the strategy: up = value, down = momentum and center = risk-free. A moving average is overlaid for visualization of the market regime. The strategy typically switches 7 times per year.

Notice how the strategy moves aggressively into value after the recessions of 2002 and 2008 . Daniel and Moskowitz (2013) find that momentum portfolios strongly underperform during this type of recovery or 'rebound' period. 


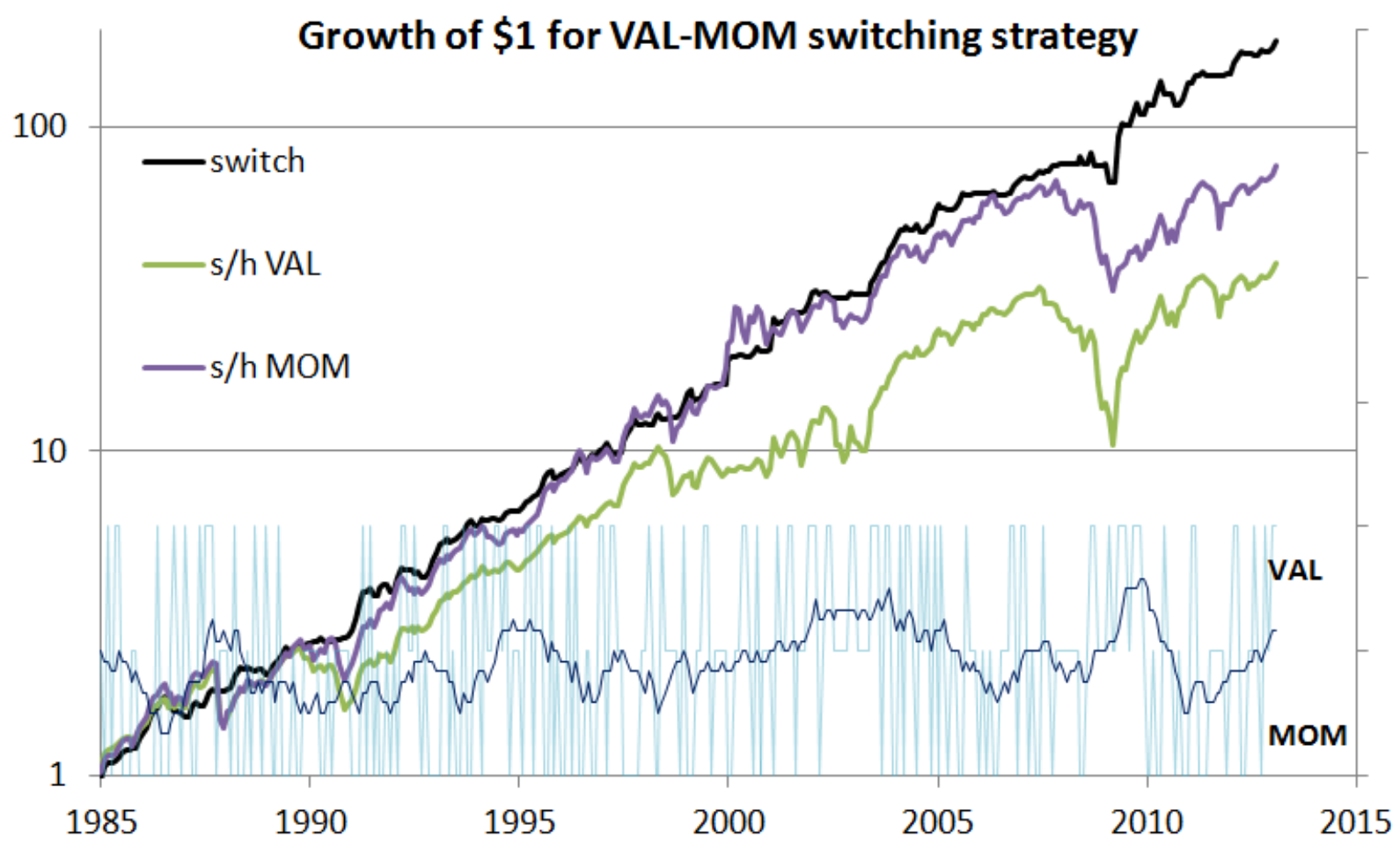

Figure 1: Growth of \$1 for the value-momentum switching strategy

\subsection{Factor analysis}

The portfolio returns were regressed on the risk factors using equation (1). Results are shown in table 4.

Table 4: Portfolio factor analysis

\begin{tabular}{|c|cc|cc|cc|}
\cline { 2 - 8 } \multicolumn{1}{c|}{} & \multicolumn{2}{c|}{ VAL } & \multicolumn{2}{c|}{ MOM } & \multicolumn{2}{c|}{ switch } \\
\hline & Coefficients & $t$ Stat & Coefficients & t Stat & Coefficients & $t$ Stat \\
\hline Intercept & 0.06 & 0.45 & 0.40 & 2.57 & 0.98 & 5.24 \\
Mkt-RF & 1.13 & 40.95 & 1.12 & 32.14 & 0.41 & 9.72 \\
SMB & 0.84 & 20.73 & 0.54 & 10.56 & 0.50 & 8.10 \\
HML & 0.67 & 15.63 & 0.24 & 4.54 & 0.22 & 3.42 \\
\hline Adjusted R $\mathrm{R}^{2}$ & \multicolumn{2}{|c|}{0.87} & \multicolumn{2}{c|}{0.79} & \multicolumn{2}{c|}{0.35} \\
\hline
\end{tabular}


All portfolios load heavily on size, as expected due to the small portfolios used. Loading on the market factor, also known as beta, is slightly above one for the base portfolios. Beta is much lower for the switching strategy but the regression fit $\left(R^{2}\right)$ is poor. Adding the momentum factor (UMD) does not improve $\mathrm{R}^{2}$ therefore those results are omitted.

\subsection{Implementation costs}

\section{Annual fees}

Small value funds such as $\mathrm{VBR}^{1}$ are available for 10 basis points (bp) annually. Small momentum funds (for example DWAS ${ }^{2}$ ) are a more recent innovation and cost in the range of $60 \mathrm{bp}$. Assuming equal time in each fund, annual fees could average $35 \mathrm{bp}$.

\section{Commissions and slippage}

With today's fixed brokerage costs, use of liquid funds and generous allowance for slippage, trades could be completed for $5 \mathrm{bp}$. Annual trading costs for 7 round-trip trades total $70 \mathrm{bp}$.

Therefore the total implementation costs, excluding taxes, are $105 \mathrm{bp}$ annually. This is a fifth of the strategy excess return over the underlying component average.

\section{Robustness checks}

To check robustness, I repeated the calculations for the equally-weighted small value and momentum portfolios. The results are shown in table 5.

1. Vanguard Small-Cap Value ETF on NYSE

2. PowerShares DWA Small Cap Momentum Portfolio on NASDAQ 
Table 5: Value-momentum strategy with equal-weight (ew) portfolios

\begin{tabular}{|c|c|c|c|}
\hline 1984-2014 & VAL(ew) & MOM(ew) & switch \\
\hline SR & 0.9 & 0.9 & 1.6 \\
\hline t-stat & 5.0 & 4.9 & 8.7 \\
\hline CAGR & $17.3 \%$ & $18.0 \%$ & $23.2 \%$ \\
\hline $\mathbf{R}^{2}$ & $96.7 \%$ & $96.7 \%$ & $99.5 \%$ \\
\hline
\end{tabular}

SR Sharpe Ratio, CAGR Compound Annual Growth Rate, VAL Value, MOM Momentum

Performance is higher across the board for equal-weight portfolios (but may not be practically realizable due to large positions in illiquid stocks). However, for the purpose of comparison, the results show that the strategy generates a $78 \%$ improvement in Sharpe Ratio and an annual return increase of $5.6 \%$ over the base portfolio average.

Finally, the calculations were repeated for the time period from 1954 to 1984 . Tests are frictionless which, as alluded to in the methodology section, would be less realistic for this epoch. The results are shown in table 6 .

Table 6: Value-momentum strategy from 1954 to 1984

\begin{tabular}{|c|c|c|c|}
\hline 1954-1984 & VAL & MOM & switch \\
\hline SR & 1.0 & 1.1 & 1.5 \\
\hline t-stat & 5.4 & 5.9 & 8.1 \\
\hline CAGR & $18.6 \%$ & $21.8 \%$ & $20.5 \%$ \\
\hline $\mathbf{R}^{\mathbf{2}}$ & $96.4 \%$ & $96.1 \%$ & $96.2 \%$ \\
\hline
\end{tabular}

SR Sharpe Ratio, CAGR Compound Annual Growth Rate, VAL Value, MOM Momentum

The strategy underperforms momentum by $1.3 \%$ annually on an absolute basis but the Sharpe Ratio of the strategy is $50 \%$ greater than the value portfolio and $36 \%$ superior to the 
momentum portfolio. Thus the risk adjusted returns are substantially larger. The strategy $\mathrm{t}$ statistic is higher than the base portfolios and $R^{2}$ is similar throughout.

\section{Concluding Remarks}

The analyses in this paper show that the monthly autocorrelation property of the HML (or "value") factor can be reliably exploited to form an investment strategy. A strategy which switches capital from value to momentum portfolios based on the sign of the factor is demonstrated to have superior absolute and risk adjusted performance to the underlying instruments.

The questions posed in the introduction have been answered as follows:

1. It is possible to reliably allocate capital using factor autocorrelation.

2. The costs of implementing such a strategy are a fifth of the excess returns.

3. The strategy uses liquid, low-cost funds and trades 7 times per year, therefore is readily implementable by the individual investor. 


\section{Bibliography}

Antonacci, G., 2012, Risk Premia Harvesting Through Dual Momentum

Asness, C. S., T. J. Moskowitz, and L.H. Pedersen, 2013, Value and momentum everywhere, The Journal of Finance 58, 929-895.

Berger A.L., Israel R. and Moskovitz T.J., 2009, The Case for Momentum Investing, AQR White Paper

Daniel K.D. and Moskowitz T.J., 2013, Momentum Crashes, Working Paper

Doskov, N., Pekkala, T., Ribeiro, R., 2013, Tradable Aggregate Risk Factors and the CrossSection of Stock Returns.

Faber, M., 2007, A Quantitative Approach to Tactical Asset Allocation, Journal of Wealth Management, Spring 2007

Fama, E. F., French, K. R., 1992, The Cross-Section of Expected Stock Returns, Journal of Finance

47, pp. 427-465.

Fama, E. F., French, K. R., 1993, Common risk factors in the returns on stocks and bonds, Journal of Financial Economics 33, 3-56.

Fama, E. F., French, K. R., 2012, Size, Value, and Momentum in International Stock Returns

Israel R. and T.J. Moskowitz, 2013, The role of shorting, firm size, and time on market anomalies, Journal of Financial Economics 108, 275-301. 
Kothari and Shanken, 1998, Beta and Book-to-Market: Is the Glass Half Full or Half Empty?

Loughran, T., 1997. Book-to-market across firm size, exchange, and seasonality: Is there an effect? Journal of Financial and Quantitative Analysis 32, 249-268.

Sharpe, W. F., 1964, Capital asset prices: A theory of market equilibrium under conditions of risk, Journal of Finance 19, pp. 425-442. 